\title{
DIGLOSIA
}

Terakreditasi Sinta 3 | Volume 3 | Nomor 3 | Tahun 2020 | Halaman 295-304

P-ISSN 2615-725X | E-ISSN 2615-8655

http://diglosiaunmul.com/index.php/diglosia/article/view/77

\section{PEMERTAHANAN BAHASA DAYAK KENYAH DI KOTA SAMARINDA}

\author{
Preservation of Dayak Kenyah Language in Samarinda
}

\author{
Kiftian Hady Prasetya ${ }^{1, *}$, Hani Subakti ${ }^{2}$, dan Hety Diana Septika ${ }^{3}$ \\ ${ }^{1}$ Universitas Balikpapan \\ ${ }^{2}$ Universitas Widya Gama Mahakam \\ ${ }^{3}$ Universitas Mulawarman \\ 1,* Pos-el korespondensi: kiftian@uniba-bpn.ac.id \\ ${ }^{2}$ Pos-el: hanisubakti@uwgm.ac.id \\ ${ }^{3}$ Pos-el: hety.diana@ffkip.unmul.ac.id
}

\begin{abstract}
The focus of the problem in this study is motivated by the phenomenon of the development of the times and the rapid flow of globalization making the Dayak ethnic in Samarinda City specifically, becoming an ethnic minority so language retention needs to be made in multilingual minority language communities. The language that is the focus of research is Dayak Kenyah Language. The purpose of this study was to determine the factors of preservation of Dayak. Kenyah Language in Samarinda City. This research uses descriptive qualitative method with a sociolinguistic approach. The research data were written text (conversational transcripts) from the data source of the Dayak Kenyah ethnic community in Samarinda City. Data collection techniques using the stages of observation, Simak. Free Engage Involved (SBLC) techniques, and interviews. Research instruments in the form of devices, stationery, notebooks, and indicators of language maintenance. The results of the study found that there were efforts made by the Dayak Kenyah community in Samarinda City as a manifestation of the language of the Dayak Kenyah region. The research findings are: (1) family factors, (2) social factors, (3) communication intensity factors, (4) activity factors, and (5) desire factors in language retention. The conclusion in this study focuses more on the care and contribution of various layers of ethnic Dayak Kenyah communities, especially in Samarinda, towards the regional languages they have.
\end{abstract}

Keywords: sociolinguistics, language preservation, Dayak. Kenyab language

\begin{abstract}
Abstrak: Fokus masalah dalam penelitian ini dilatarbelakangi oleh fenomena berkembangnya zaman dan derasnya arus globalisasi membuat etnis Dayak di Kota Samarinda secara khusus, menjadi etnis minoritas sehingga perlu dilakukan pemertahanan bahasa pada masyarakat bahasa minoritas yang multilingual. Bahasa yang menjadi fokus penelitian adalah Bahasa Dayak Kenyah. Tujuan penelitian ini untuk mengetahui faktor-faktor pemertahanan Bahasa Dayak Kenyah di di Kota Samarinda. Penelitian ini menggunakan metode kualitatif deskriptif dengan pendekatan sosiolinguistik. Data penelitian ini berupa teks tulis (transkrip percakapan) dari sumber data masyarakat etnis Dayak Kenyah di Kota Samarinda. Teknik pengumpulan data menggunakan tahapan observasi, teknik Simak Bebas Libat Cakap (SBLC), dan wawancara. Instrumen penelitian berupa gawai, alat tulis, buku catatan, dan tabel indikator pemertahanan bahasa. Hasil penelitian menemukan adanya upaya-upaya yang dilakukan masyarakat Dayak Kenyah di Kota Samarinda sebagai wujud pemertahan Bahasa daerah Dayak Kenyah. Temuan penelitian berupa: (1) faktor keluarga, (2) faktor pergaulan, (3) faktor intensitas komunikasi, (4) faktor kegiatan, dan (5) faktor keinginan dalam pemertahanan bahasa. Kesimpulan dalam penelitian ini lebih menitikberatkan pada kepedulian dan kontribusi pelbagai lapisan masyarakat etnis Dayak Kenyah khususnya di Kota Samarinda terhadap bahasa daerah yang dimiliki.
\end{abstract}

Kata kunci: sosiolinguistik, pemertahanan bahasa, bahasa Dayak Kenyah 


\section{A. PENDAHULUAN}

Manusia merupakan makhluk sosial yang selalu berinteraksi satu sama lain, baik secara verbal, tulisan, maupun interaksi dalam bentuk isyarat, sehingga pengkajian bahasa tidak dapat dipisahkan dari peradaban manusia. Prasetya (2018) menyatakan bahwa ditilik dari fungsi bahasa secara tradisional, fungsi bahasa adalah sebagai alat komunikasi yang memiliki fungsi khusus yakni menjalin hubungan solidaritas, dan kerja sama dalam masyarakat, bahasa untuk menyatakan pikiran dengan perasaan sehingga pendengar mampu merasakan apa yang akan sedang dibicarakan.

Bahasa itu bersifat organis (seperti mahluk hidup) dan karena itu, bahasa mempunyai rentangan hidup dan ada waktu yang dijanjikan (dijadwalkan). Keduanya mempunyai masa bayi (infancy), dasar dan awal, mempunyai pertumbuhan dan peningkatan dalam kemurnian dan kesempurnaan, begitu pula dalam penyebaran, dan pengembangbiakan, ketegaran, masa tua, rentang (merosot), dan rusak (Sumarsono, 2006).

Asal-usul bahasa itu sangat berlainan tergantung pada faktor-faktor yang mengatur tumbuhnya bahasa itu (Chaer, 2003). Bahasa merupakan suatu unsur pokok yang terdapat dalam masyarakat. Bahasa yang digunakan oleh masyarakat sangat beragam. Diperkirakan jumlah bahasa di dunia antara 6.000-7.000 bahasa, sedangkan di Indonesia, memiliki 748 bahasa yang masih hidup dan bertahan.

Dari banyaknya ragam bahasa yang dimiliki Indonesia inilah yang menjadikan masyarakat di Indonesia menjadi masyarakat yang multilingual. Masyarakat Indonesia berawal dari masyarakat monolingual yakni lebih dahulu menguasai bahasa daerah sebagai bahasa ibu dan selanjutnya berkembang menjadi masyarakat bilingual atau multilingual.
Fenomena masyarakat multilingual yang menarik untuk diamati dalam penggunaan bahasa, secara khusus dalam penelitian ini difokuskan pada Kota Samarinda. Kota Samarinda terletak di Provinsi Kalimantan Timur yang mayoritas masyarakatnya adalah imigrasi seperti etnis Kutai, Banjar, Jawa, Madura, Bugis, dan Dayak. Etnis Dayak merupakan etnis pertama yang berada di Pulau Kalimantan.

Permasalahan yang terjadi, seiring berkembangnya zaman dan derasnya arus globalisasi membuat etnis Dayak di Kota Samarinda secara khusus, menjadi etnis minoritas. Masyarakat etnis Dayak yang berimigrasi di Kota Samarinda menjadi masyarakat yang bilingual, bahkan multilingual.
"Istilah bilingual disebut juga kedwibahasaan yaitu berkenaan dengan menggunakan dua bahasa yang dapat diartikan sebagai penggunaan dua bahasa oleh seorang penutur dalam pergaulannya dengan orang lain secara bergantian. Sedangkan istilah multilingual disebut sebagai keanekabahasawanan yakni keadaan digunakannya lebih dari dua bahasa oleh seseorang dalam pergaulannya dengan orang lain secara bergantian" (Chaer, 2003).

Berdasarkan pandangan tersebut, maka dapat dimaknai bahwa etnis Dayak yang berada di Kota Samarinda tidak hanya menggunakan Bahasa Dayak, tetapi mereka juga menguasai Bahasa Indonesia dan Bahasa Dayak. Hal itu terlihat pada observasi awal yang dilakukan peneliti saat berada di lingkungan masyarakat etnis Dayak Kenyah yang melakukan percakapan.

Pada saat percakapan yang terjadi dominannya menggunakan bahasa Indonesia, maka penutur Bahasa Dayak menyesuaikan penggunaan bahasanya. Kemudian, pada saat berada di perkumpulan etnis Dayak Kenyah, maka 
Bahasa yang digunakan adalah bahasa Dayak Kenyah. Perlakuan tersebut dapat digolongkan sebagai suatu wujud dari pemertahanan Bahasa, dalam hal ini pemertahanan Bahasa Dayak Kenyah.

Pemertahanan bahasa merupakan cara untuk menjaga dan melestarikan suatu bahasa agar mengurangi dampak pergeseran bahasa bahkan dapat menjadi alternatif dari kepunahan bahasa. Pemertahanan bahasa lebih menyangkut sikap atau penilaian terhadap suatu bahasa, untuk tetap menggunakan bahasa tersebut di tengah-tengah bahasa lainnya (Chaer, 2003). Selanjutnya, Sumarsono (2006) mengungkapkan bahwa dalam pemertahanan bahasa suatu komunitas secara kolektif menentukan untuk melanjutkan memakai bahasa yang sudah biasa dipakai.

Mendukung pernyataan tersebut, Nisah, Prasetya, \& Musdolifah (2020) menyatakan bahwa pemertahanan bahasa terjadi pada suatu masyarakat bahasa yang masih terus menggunakan bahasa ibunya pada penggunaan bahasa yang biasanya secara turun-temurun dikuasai oleh penutur bahasa tersebut. Dari pelbagai pandangan tersebut dapat dimaknai bahwa hubungan masyarakat dan bahasa sangatlah erat, yang dapat membuat suatu bahasa bertahan, bergeser, maupun mengalami kepunahan.

Pelbagai penelitian yang berkaitan dengan pemertahanan bahasa sebagai data empiris yang menunjang penelitian ini dan sebagai langkah solutif dari kepunahan bahasa-bahasa daerah pernah dilakukan oleh beberapa ahli bahasa.

Tondo (2009) dengan judul penelitian "Kepunaban Bahasa-Babasa Daerah: Faktor Penyebab dan Implikasi Etnolinguistis", memberikan informasi kepada masyarakat bahasa bahwa kepunahan bahasa merupakan sesuatu hal yang dapat dicegah dengan beberapa teknik dan cara yang benar dan efektif dalam masyarakat pengguna bahasa daerah.
Kemudian, Istianingrum (2015) dengan judul penelitian "Eksistensi Bahasa Dayak Kenyah di Kota Balikpapan, Kalimantan Timur", memberikan informasi dan hasil penelitian mengenai pentingnya pemertahanan bahasa terhadap pergeseran-pergeseran bahasa yang terjadi pada masyarakat multicultural di Kalimantan Timur.

Setelah itu, Alika (2017) dengan judul penelitian "Faktor Pemertabanan Babasa Minangkabau Ragam Nonformal dalam Ranah Kekariban pada Komunitas Seni Sakato di Kota Yogyakarta”. Berdasarkan hasil analisis data, faktor pemertahanan bahasa Minangkabau ragam nonformal dalam ranah kekariban pada komunitas seni sakato di Kota Yogyakarta meliputi faktor keluarga, faktor pergaulan, faktor intensitas komunikasi, faktor kegiatan, dan faktor keinginan.

Selanjutnya, Ernawati \& Usman (2019) yang berjudul "Pergeseran Bahasa Masyarakat Etnis Tionghoa di Bima" dalam penelitiannya menunjukkan bahwa ada dua hasil terhadap penelitiannya, yang pertama bahwa faktor-faktor penyebab terjadinya pergeseran bahasa masyarakat etnis Tionghoa ada tiga, yakni faktor imigrasi, faktor sosial, dan faktor ekonomi. Lalu hasil penelitian yang kedua dampak pergeseran Bahasa ada dua, yaitu dampak positif dan dampak negatif.

Perbedaan data empiris dari penelitian yang telah dilakukan para ahli tersebut terletak pada objek yang diamati. Pada penelitian ini focus objek yang diamati adalah pemertahanan Bahasa Dayak Kenyah yang berda di Kota Samarinda. Sedangkan persamaan penelitian ini dengan data empirirs tersebut terdapat pada penggunaan indikator pemertahanan bahasa menurut Downes (dalam Alika, 2017) yang berupa:

(1) faktor keluarga, (2) faktor pergaulan, (3) faktor intensitas komunikasi, (4) faktor kegiatan, dan (5) faktor keinginan.

Faktor keluarga merupakan unit terkecil dari masyarakat yang terdiri atas 
kepala keluarga dan beberapa orang yang terkumpul. Diharapkan dalam keluarga tersebut perilakunya memperlihatkan bahwa yang bersangkutan mempergunakan bahasa sesuai ranah bahasanya.

Faktor pergaulan merupakan jalinan hubungan sosial antara seseorang dengan orang lain yang berlangsung dalam jangka relatif lama sehinga terjadi saling mempengaruhi satu dengan lainnya. Dalam pemertahanan bahasa, jika bahasa tersebut masih digunakan maka hal ini menunjukkan adanya kebanggaan terhadap bahasa tersebut.

Selanjutnya, faktor intensitas
komunikasi merupakan tingkat kedalaman pesan dan juga keluasan pesan yang disampaikan kepada orang lain. $\mathrm{Hal}$ ini dapat dilihat berdasarkan keseringannya menggunakan bahasa dalam kehidupan sehari-hari.

Faktor kegiatan merupakan suatu aktivitas manusia yang dilakukan seharihari. Seperti aktivitas dalam keikutsertaan/keanggotaan di bidang seni maupun agama dan lain sebagainya.

Terakhir, faktor keinginan merupakan segala kebutuhan lebih terhadap barang ataupun jasa yang ingin dipenuhi setiap manusia pada sesuatu hal yang dianggap kurang. Pada pemertahanan bahasa harapannya akan bahasa sendiri, apakah anaknya juga diajarkan dan dituntut untuk menggunakan bahasa tersebut.

Berdasarkan landasan teoretis tersebut, maka sangat penting dan mendesak agar dilakukan penelitian untuk mengetahui pemertahanan Bahasa Dayak Kenyah di Kota Samarinda. Selain itu, secara objektif peneliti tertarik untuk menganalisis dan meneliti faktor-faktor pemertahanan Bahasa Dayak Kenyah di Kota Samarinda dengan aspek sosiolinguistik.

Selanjutnya, manfaat penelitian ini dapat dijadikan pengetahuan di luar pendidikan formal akibat pergeseran bahasa dan ancaman kepunahan bahasa daerah bila tidak ada pemertahanan bahasa oleh masyarakat pengguna Bahasa itu sendiri.

\section{B. METODE}

Penelitian ini merupakan penelitian kualitatif. Penelitian kualitatif sebagai prosedur penelitian yang menghasilkan data deskriptif berupa kata-kata tertulis atau lisan dari orang-orang dan perilaku yang dapat diamati. Metode yang digunakan dalam tulisan ini adalah metode deskriptif. Metode deskriptif untuk memaparkan data dan menguraikannya sesuai dengan sifat alamiah data yang diperoleh (cara menuturkan, mengklasifikasikan, dan menganalisisnya). Metode penelitian kualitatif dalam penelitian ini bertujuan untuk mendeskripsikan pemertahanan bahasa Dayak Kenyah di Kota Samarinda.

Pada penelitian ini, pemertahanan bahasa yang berupa (1) faktor keluarga, (2) faktor pergaulan, (3) faktor intensitas komunikasi, (4) faktor kegiatan, dan (5) faktor keinginan akan dideskripsikan dan dianalisis menggunakan perspektif pendekatan sosiolinguistik. Pendekatan sosiolinguistik digunakan dengan landasan untuk mengetahui faktor-faktor pemertahanan bahasa Dayak Kenyah di Kota Samarinda. Pendekatan ini dinilai tepat untuk mengkaji tentang ciri khas variasi bahasa dalam kaitannya dengan penggunaan bahasa dalam masyarakat.

Berdasarkan hal tersebut, jenis penelitian ini merupakan penelitian deskriptif kualitatif dengan pendekatan sosiolinguistik yang bertujuan untuk mendeskripsikan secara sistematis, faktual dan akurat dari fenomena atau objek tertentu, yaitu pemertahanan bahasa Dayak Kenyah di Kota Samarinda.

Dalam penelitian ini sumber data yaitu masyarakat etnis Dayak Kenyah yang bermukim pada wilayah Banggeris, Gunung Lingai, dan Loa Jalan Ilir di Kota 
Samarinda. Data penelitian ini berupa teks tertulis hasil transkrip percakapan pada Desember 2019 hingga Januari 2020 oleh masyarakat etnis Dayak Kenyah di Kota Samarinda.

Teknik pengumpulan data yang digunakan pada penelitian ini antara lain adalah teknik observasi. Pengumpulan data dilakukan dengan cara mengamati fenomena-fenomena yang terkait dengan upaya-upaya pemertahanan Bahasa Dayak Kenyah di Kota Samarinda. Selanjutnya, wawancara digunakan sebagai teknik pengumpulan data karena peneliti ingin melakukan studi pendahuluan untuk menemukan permasalahan yang akan diteliti dan juga peneliti ingin mengatahui hal-hal dari responden yang lebih mendalam. Wawancara yang dilakukan peneliti dalam hal ini adalah wawancara tidak terstruktur. Kemudian, teknik Simak Bebas Libat Cakap (SBLC) dilakukan oleh peneliti dengan hanya menyimak percakapan yang dilakukan oleh penutur Bahasa Dayak Kenyah. Selain menyimak, peneliti juga mencatat hal-hal penting mengenai perilaku setiap narasumber dalam peristiwa tutur. Dalam melakukan teknik ini, peneliti juga melakukan teknik rekam, yaitu merekam percakapan atau pembicaraan informan. Rekaman tersebut ditranskip dengan teknik catat. Dari hasil rekaman, peneliti dapat memperhatikan penggunaan bahasa yang digunakan oleh masyarakat penutur.

Instrumen penelitian berupa gawai, alat tulis, buku catatan, dan tabel indikator pemertahanan Bahasa Dayak Kenyah di Kota Samarinda. Peneliti menggunakan teknik analisis data model dari Miles and Huberman (dalam Sugiyono, 2016) mengemukakan bahwa aktivitas dalam analisis data kualitatif dilakukan secara terus menerus sampai tuntas, sehingga datanya sudah jenuh. Aktivitas dalam analisis data yaitu reduksi data (data reduction), penyajian data (data display), dan penarikan simpulan (verification).
Pada penelitian ini juga menggunakan perspektif emik dan etik yang digunakan agar dalam tahapan analisis data, peneliti benar-benar memahami dan menginterpretasi data sesuai dengan sudut pandang budaya setempat. Mengenai perspektif emik etik Harris (dalam Prasetya, 2016) menyatakan bahwa hal pertama memahami budaya disebut dengan emik dan yang kedua adalah etik. Emik adalah konsep dari pandangan yang nyata dari sebuah data asli dan etik merupakan konsep dan pemaknaan dari peneliti. Lebih jelas, perspektif emik berperan saat pemaknaan dan penafsiran tuturan Bahasa Dayak Kenyah di Kota Samarinda yang ditemukan tidak terlepas dari konteks situasi dan konteks budaya yang melekat pada data penelitian, yang terjadi saat percakapan berlangsung. Selanjutnya, perspektif etik berperan saat peneliti mereduksi dan menganalisis data yang ditemukan yang kemudian mengaikaitkan dengan fenomena dan sudut pandang penggunaan bahasa secara umum.

\section{PEMBAHASAN}

Hasil penelitian menemukan adanya upaya-upaya yang dilakukan masyarakat Dayak Kenyah di Kota Samarinda sebagai wujud pemertahanan Bahasa Dayak Kenyah di Kota Samarinda. Temuan penelitian berupa: (1) faktor keluarga, (2) faktor pergaulan, (3) faktor intensitas komunikasi, (4) faktor kegiatan, dan (5) faktor keinginan.

\section{Faktor Keluarga}

Faktor keluarga merupakan unit terkecil dari masyarakat yang terdiri atas kepala keluarga dan beberapa orang yang terkumpul. Diharapkan dalam keluarga tersebut perilakunya memperlihatkan bahwa yang bersangkutan mempergunakan bahasa sesuai ranah bahasanya.

Berikut disajikan transkrip percakapan yang dilakukan oleh 
masyarakat etnis Dayak Kenyah dalam ranah keluarga.

\section{Data 1.}

Konteks: percakapan antara masyarakat etnis Dayak Kenyah dalam ranah keluarga yang membicarakan mengenai permintaan untuk berbelanja.

P1 : anak, akeq nyat lesau cok ikoq tay nemeli atok badang ngan tilo iyap kak juma ne adeng

P2 : abaq weq, naq uang uleq e makeq op baha

P3 : amai seq keq ubaq ke cok ikoq ke meli pulsa are, pakai uang uneq koq ne kena adeng.

P2 : amai ni, kediot ne uleq e o.

P1 : ahaq ni amai ni, main cok-cok beq po iya naq uang gok le ke nemeli miya po.

P3 : abaq apan liwai ni le $p$, abeq inu on ko.

\section{Terjemahan}

P1 : Nak, tolong belikan sarden dan telur dulu di warung depan

P2 : iya Mah. Uang kembalian buat saya ya. Haha

P3 : Bapak titip pulsa nak. Pakai uang ibu aja.

P2 : Bapak ini, kurang sudah uang kembalian

P1 : iya nih bapak main titip-titip aja tapi tidak kasih uang buat beli.

P3 : ya sekali-kali tidak apa lah.

Data 1 tersebut merupakan hasil transkrip dari percakapan masyarakat etnis Dayak Kenyah di Kota Samarinda. Percakapan terjadi dalam ranah keluarga yang membicarakan mengenai permintaan orang tua kepada seorang anak untuk pergi berbelanja.

Hasil analisis menunjukkan bahwa kondisi pemertahanan Bahasa Dayak Kenyah pada faktor keluarga stabil dan bertahan. Hal tersebut dapat diamati dari percakapan yang terjadi antara orang tua terhadap anaknya sendiri. Pada konteks nonformal yang terjadi, sering sekali terjadi pergeseran bahasa dari seorang anak saat menanggapi bahasa yang digunakan oleh orang tuanya. $\mathrm{Hal}$ tersebut biasanya terjadi karena lingkungan formal dan nonformal dari seorang anak yang sudah berada pada ranah masyarakat yang multilingual.

Namun, pada data tersebut tidak ditemukan adanya peralihan bahasa sebagai satu tanda pergeseran bahasa. Data tersebut menandakan bahwa pada ranah keluarga, orang tua secara khusus selalu memberikan Bahasa Dayak Kenyah secara stimulan dalam setiap komunikasi yang terjadi di lingungan keluarga. Perilaku memperlihatkan dan mempergunakan bahasa sesuai ranah bahasanya ini merupakan salah satu syarat pemertahanan bahasa dalam faktor keluarga.

\section{Faktor Pergaulan}

Faktor pergaulan merupakan jalinan hubungan sosial antara seseorang dengan orang lain yang berlangsung dalam jangka relatif lama sehinga terjadi saling mempengaruhi satu dengan lainnya. Dalam pemertahanan bahasa, jika bahasa tersebut masih digunakan maka hal ini menunjukkan adanya kebanggaan terhadap bahasa tersebut.

Berikut disajikan transkrip percakapan yang dilakukan oleh penutur muda masyarakat etnis Dayak Kenyah.

\section{Data 2.}

Konteks: percakapan antara penutur muda Dayak Kenyah yang membicarakan peluang pertanian dalam situasi candaan.

P1 : laku bawang le dulu ney meli kiq?

P2 : a a uyan taban penyakit dalem.

P1 : moq inu le raun muka koq ini neh!

P2 : canaan tanah kini neh. Kini ne tipan layap.

P1 : haba aa bawang ilu mula kini, moq yaq nay modip.

P2 : hababa ikaq ini. 


\section{Terjemahan}

P1 : bawang kita di sini laris dibeli orang ya.

P2 : iya, katanya buat obat penyakit dalam.

P1 : kenapa nggak kita tanam aja di sini.

P2 : tanah di sini beda sama tempat kita. Di sini tanah sering kena banjir.

P1 : haha. Iya. Bawang kita tanam di sini, sampah yang tumbuh.

P2 : hahaha. Kau ini.

Data 2 tersebut merupakan hasil transkrip dari percakapan yang dilakukan penutur muda dengan rentang usia yang sepadan dari masyarakat etnis Dayak Kenyah di Kota Samarinda yang membicarakan tentang peluang bercocok tanam bawang khas Dayak Kenyah yang tinggi peminatnya di Kota Samarinda. Penutur membicarakan hal tersebut dengan perbandingan tempat asal dan tempat yang dihuni saat ini.

Hasil analisis menunjukkan bahwa kondisi pemertahanan Bahasa Dayak Kenyah pada faktor pergaulan masih tergolong stabil dan bertahan. Hal tersebut dapat diamati dari percakapan yang berada dalam konteks non formal yang sering dilakukan oleh penutur muda etnis Dayak Kenyah di Kota Samarinda.

Adanya faktor pendidikan yang dimiliki penutur muda tersebut tidak memengaruhi penggunaan bahasa pertamanya dalam pergaulan. Tentunya penyesuaian lingkungan dengan mayoritas pengguna Bahasa Indonesia dan Bahasa Banjar di Kota Samarinda menjadi pemantik yang sukar untuk dihindarkan bagi penutur muda untuk beralih bahasa saat melakukan percakapan.

Namun, Bahasa Dayak Kenyah masih digunakan oleh penutur tersebut. Maka, hal ini menunjukkan adanya kebanggaan terhadap Bahasa Dayak Kenyah sebagai bahasa pertama atau sebagai bahasa ibu yang mereka miliki sehingga hal tersebut tergolong sebagai syarat dari faktor pergaulan dalam pemertahanan bahasa.

\section{Faktor Intensitas Komunikasi}

Faktor intensitas komunikasi merupakan tingkat kedalaman pesan dan juga keluasan pesan yang disampaikan kepada orang lain. Hal ini dapat dilihat berdasarkan keseringannya menggunakan bahasa dalam kehidupan sehari-hari.

Berikut disajikan transkrip percakapan yang dilakukan oleh beberapa penutur masyarakat etnis Dayak Kenyah.

\section{Data 3.}

Konteks: percakapan antara penutur Dayak Kenyah yang membicarakan gangguan sinyal pada gawai mereka. Kemudian percakapan beralih topik membahas pemilihan ketua BUMN yang sedang ramai diberitakan oleh mediamedia Indonesia.

P1 : moq inu youtobe ini raun ubaq buka?

P2 : awi pan gangguan.

P1 : anun nguk?

P2 : aaq kiq buka whatsap mpi njam, monge gangguan.

P3 : njam tah anun kiq, ukoq le raun uba pakain kartu yaq jarang gratisan bahaha.

P1 : tiga dan pisiu, mpi sen aun, harus tutui le.

P3 : ca pilihan tanah, pakai kadoq gratis, kadoq te knah aa pooh, haha.

P2 : sabar le ne pe.

P1 : moq inu media ini pebiyo masa lalu dunia.

P2 : pernah yaq penjara, ukoq an pebiyo berita dulu.

P3 : oo, yaq pernah jadi gubernur ina rey mu, 3 te ya gayang aun aturan ngn empi ya korupsi.

P1 : aa.lan teb ina setuju.

P4 : midan de tesan i, yaq korupsi. njam tia koropsi. gayeng koq ira kadoq sen yaq pelapa.

P1 : Habaha. Lain ina. 
P3 : akeq yakin iya njam pimpin, negara le maju.

\section{Terjemahan}

P1 : kenapa youtube ini, kok nggak bisa terbuka dari tadi?

P2 : gangguan paling.

P1 : punyamu juga?

P2 : iya nah. Aku dari tadi buka whatsapp nggak bisa-bisa. Gangguan semuanya barangkali.

P3 : punyaku bisa kok. Kartunya paling. Makanya pakai kartu yang jarang gratisan.

P1 : enak saja kau ngomong, duit tipis. Harus hemat.

P3 : ya pilihan itu. Pakai banyak gratisan ya gratis juga nunggunya. Haha.

P2 : sabar aja sudah kalua begini.

P1 : kenapa juga media ini membesar2kan masa lalu orang. Padahal bagus juga dia jadi dirut BUMN

P2 : dia pernah masuk penjara, makanya dibesar-besarkan beritanya.

P3 : oh, mantan gubernur itu kah. Memang bagus dia bekerja, punya aturan dan tak mungkin korupsi.

P1 : betul itu, setuju aku.

P4 : mana kau tau, mungkin dulu nggak korupsi. Nanti bisa2 korupsi. Kerja di situ banyak uang yang lewatlewat.

P2 : Hahaha. Benar juga itu.

P3 : tapi saya yakin kalau seperti dia yang pimpin, maju kita punya negara.

Data 3 tersebut merupakan transkrip percakapan masyarakat etnis Dayak Kenyah di Kota Samarinda yang membicarakan

Hasil analisis menunjukkan bahwa kondisi pemertahanan Bahasa Dayak Kenyah pada faktor intensitas komunikasi masih bertahan dan stabil karena terjalin dengan durasi yang panjang serta sangat sering dilakukan oleh masyarakat etnis Dayak Kenyah di Kota Samarinda.
Tingkat kedalaman pesan dan keluasan pesan terdapat dalam percakapan yang dilakukan tersebut. Peralihan topik dengan durasi yang panjang dan tetap menggunakan Bahasa Dayak Kenyah merupakan salah satu syarat dari faktor intensitas komunikasi dalam pemertahanan bahasa.

\section{Faktor Kegiatan}

Faktor kegiatan merupakan suatu aktivitas manusia yang dilakukan seharihari. Seperti aktivitas dalam keikutsertaan/keanggotaan di bidang seni maupun agama dan lain sebagainya.

Berikut disajikan transkrip percakapan yang dilakukan oleh beberapa penutur masyarakat etnis Dayak Kenyah.

\section{Data 4.}

Konteks: percakapan antara penutur muda dan penutur tua masyarakat etnis Dayak Kenyah yang membicarakan mengenai kegiatan Tari Kancet Papatai.

P1 : madek koq labo ben nai po

P2 : un njem nadeng ne, seq amai pelatih pekena kenai le on mong le p ini.na le ilu ke nadeng ge.

P1 : ikoq ini. Lepa tapa beq p ikoq ngkin alat la'a. empi sapai kacet koq?

P2 : maaf amai, sapai kacet keq, akeq linggo

P3 : ca liwai ikoq sau sapai iyaq ikoq linggo na. baheng koq p ikoq linggo. Tay alaq a te larai. $\mathrm{Na}$ le ilu kenadeng nge.

P2 : maaf amai, sapai kace keq, akeq linggo

P3 : ca liwai ikoq sau sapai iyaq ikoq linggo na. baheng koq $p$ ikoq linggo. Tay alaq a te larai. Na le ilu kenadeng nge.

\section{Terjemahan}

P1 pekemsalakan bang deatimaly.pada gawai mereka. Kemudiar

P2 : sudah mulai kah? Biasa bapak pelatih tunggu lengkap baru mulai nari.

P1 : kau ini, sudah terlambat tidak bawa perlengkapan lagi. Mana baju tari kau? 
P2 : astaga, lupa lagi. Ketinggalan di pagar rumah tadi.

P3 : hei kalian, diskusi terus. Ayo segera mulai.

Hari ini kita mulai latihan tari Kancet Papatai.

Mulai dari pembukaan dulu.

P2 : maaf bapak, baju tari saya tertinggal.

P3 : lain kali bukan baju saja yang kau tinggal. Mandau pun kau tinggal. Cepat ambil kembali, baru kita mulai.

Data 4 tersebut merupakan hasil transkrip dari percakapan masyarakat etnis Dayak Kenyah di Kota Samarinda. Percakapan terjadi dalam ranah semiformal dalam latihan tari Kancet Papatai yang membicarakan mengenai kegiatan menari yang dilakukan oleh para penutur.

Hasil analisis menunjukkan bahwa kondisi pemertahanan Bahasa Dayak Kenyah pada faktor kegiatan stabil dan bertahan. Hal tersebut dapat diamati dari percakapan yang terjadi antara penutur muda dan penutur tua, dalam data ini murid tari dan guru tari.

Data 4 tersebut tidak menunjukkan adanya peralihan Bahasa yang dilakukan oleh murid tari terhadap gurunya bahkan saat meminta maaf atas kesalahan yang dilakukan oleh sang murid. Guru tari dalam data tersebut, melakukan percakapan dengan Bahasa yang digunakan oleh muridnya.

Mengingat pelatihan tari yang tidak hanya memiliki murid tari dengan latar belakang budaya dan bahasa yang sama, hal ini yang merupakan suatu pilihan yang tepat jika memnginginkan suatu Bahasa dalam hal ini Bahasa Dayak Kenyah dapat bertahan.

Pemilihan penggunaan Bahasa Dayak Kenyah terhadap muridnya yang merupakan penutur yang sama, hal ini merupakan pilihan yang tepat dan sesuai sebagai wujud pemertahanan bahasa pada faktor kegiatan.

\section{Faktor Keinginan}

Faktor keinginan merupakan segala kebutuhan lebih terhadap barang ataupun jasa yang ingin dipenuhi setiap manusia pada sesuatu hal yang dianggap kurang. Pada pemertahanan bahasa harapannya akan bahasa sendiri, apakah anaknya juga diajarkan dan dituntut untuk menggunakan bahasa tersebut.

Pada faktor keinginginan ini tidak disajikan data dalam bentuk percakapan. Namun, pada faktor ini diperkuat oleh data hasil wawancara tidak terstruktur yang dilakukan oleh peneliti.

Secara umum, hasil wawancara yang dilakukan oleh peneliti terhadap masyarakat etnis Dayak Kenyah di Kota Samarinda menghasilkan keinginan masyarakat agar Bahasa Dayak Kenyah dapat digunakan oleh masyarakat luas dalam konteks komunikasi.

Secara khusus, hasil wawancara yang dilakukan menemukan adanya keinginan dari masyarakat etnis Dayak Kenyah di Kota Samarinda menginginkan agar Bahasa Dayak Kenyah diajarkan dan di ranah formal seperti dalam pendidikan dan pengajaran.

Hasil wawancara tersebut tergolong masuk dalam faktor keinginan penutur Bahasa dalam pemertahanan bahasa karena mereka menginginkan dan memikirkan generasi mereka agar dapat menggunakan bahasa ibunya, yakni Bahasa Dayak Kenyah.

Berdasarkan fakta tersebut, disimpulkan bahwa kondisi pemertahanan Bahasa Dayak Kenyah di Kota Samarinda masih tergolong stabil dan bertahan pada faktor keluarga, faktor pergaulan, faktor intensitas komunikasi, faktor kegiatan, dan faktor keinginan.

\section{PENUTUP}

Merujuk pada masalah penelitian dan berdasarkan analisis data terhadap 
fenomena-fenomena yang ada pada pemertahanan Bahasa Dayak Kenyah di Kota Samarinda, perlu disikapi dan dicermati secara serius dan bijaksana. Berbagai faktor pemertahanan bahasa yakni faktor keluarga, faktor pergaulan, faktor intensitas komunikasi, faktor kegiatan, dan faktor keinginan masih stabil dan bertahan. Mengingat pentingnya penelitian ini dilakukan, maka perlu adanya upaya serius yang dilakukan pemerintah dan masyarakat sebagai pengguna bahasa daerah itu sendiri agar tetap kontributif dan memiliki loyalitas kepada bahasa daerahnya dengan pelbagai cara seperti pendokumentasian Bahasa Dayak Kenyah di Kota Samarinda, serta menggagas kajian-kajian dalam berbagai prespektif yang diharapkan bisa menjadi wadah untuk pemertahanan Bahasa Dayak Kenyah di Kota Samarinda sebagai wujud identitas budaya.

\section{DAFTAR PUSTAKA}

Alika, S. D. (2017). Faktor Pemertahanan Bahasa Minangkabau Ragam Nonformal dalam Ranah Kekariban pada Komunitas Seni Sakato di Kota Yogyakarta. Deiksis: Jurnal Pendidikan Bahasa dan Sastra Indonesia, 4(2), 3141.

http://jurnal.unswagati.ac.id/index.p $\mathrm{hp} /$ Deiksis/article/view/515

Chaer, A. (2003). Psikolinguistik: Kajian Teoretik. Rineka Cipta.

Ernawati, N., \& Usman. (2019). Pergeseran Bahasa Masyarakat Etnis Tionghoa di Bima. Mabasan, 13(1), $31-44$. https://mabasan.kemdikbud.go.id/i ndex.php/MABASAN/article/view $/ 246$

Istianingrum, R. (2015). Eksistensi Bahasa Dayak Kenyah di Kota Balikpapan Kalimantan Timur. Paramasastra, 2(1). https://journal.unesa.ac.id/index.ph $\mathrm{p} /$ paramasastra/article/view/1505

Nisah, N., Prasetya, K., \& Musdolifah, A. (2020). Pemertahanan Bahasa Daerah Suku Bajau Samma di Kelurahan Jenebora Kecamatan Penajam Kabupaten Penajam Paser Utara. Jurnal Basataka (JBT), 3(1), $51-65$.

https://doi.org/10.36277/basataka.v $3 \mathrm{i} 1.86$

Prasetya, K. H. (2016). Struktur Gerak dalam Wacana Interaksi Kelas di Kelas X SMA Negeri 5 Malang. Tesis Program Pascasarjana Universitas Negeri Malang.

Prasetya, K. H. (2018). Analisis Percakapan Monolog pada Acara Stand Up Comedy Metro TV. Jurnal Basataka (JBT), 1(1), 11-21. https://doi.org/10.36277/basataka.v $1 \mathrm{i} 1.17$

Sugiyono. (2016). Penelitian Kuantitatif, Kualitatif, dan R\&D. Bandung: Alfabeta.

Sumarsono. (2006). Sosiolinguistik. Yogyakarta: Pustaka Pelajar.

Tondo, H. (2009). Kepunahan BahasaBahasa Daerah: Faktor Penyebab dan Implikasi Etnolinguistis. Jurnal Masyarakat dan Budaya, 11(2), 277-96. 